\title{
Revisão bibliográfica: presença de microrganismos em aparelhos eletrônicos
}

\author{
Bibliographic review: presence of micro-organisms in electronic appliances \\ Revisión bibliográfica: presencia de microorganismos en aparatos electrónicos
}

Recebido: 23/10/2021 | Revisado: 31/10/2021 | Aceito: 02/11/2021 | Publicado: 05/11/2021

Flaviane Scheeren Figueiredo

ORCID: https://orcid.org/0000-0003-2148-6073 Universidade Federal do Pampa, Brasil

E-mail: flavianef82@gmail.com

Paula Fernanda Pinto da Costa

ORCID: https://orcid.org/0000-0002-3296-5347

Universidade Federal do Pampa, Brasil

E-mail: paulacosta@unipampa.edu.br

\begin{abstract}
Resumo
A utilização de aparelhos eletrônicos como celulares, tablets, controles remotos, notebooks, computadores foi intensificada durante a pandemia da Covid-19, onde uma grande parte da população utilizou os serviços remotos abdicando os presenciais, como serviços de banco, compras online, encomendas, deliveries, educação, como forma de manter o distanciamento. $\mathrm{O}$ presente trabalho objetivou apontar os principais microrganismos presentes em aparelhos eletrônicos, as formas de contaminação e os métodos de controle reportados na literatura. A partir desta revisão foi possível perceber o potencial para veículo de microrganismos e propagação de doenças infecciosas presentes nesses objetos. Estes são contaminados através de contato direto com a pele ou por gotículas salivares. O tempo de permanência pode variar de dias a meses dependendo do microrganismo e do material da composição da superfície. Para a prevenção e controle, já estão disponíveis no mercado recursos como películas de revestimento, baseadas na nanotecnologia que apresentam atividade antimicrobiana, que podem limitar a propagação de microrganismos. No entanto, a pesquisa por agentes químicos destinados ao uso em aparelhos eletrônicos apresenta dados escassos. A partir desse estudo é compreendido a importância das medidas preventivas e cuidados na utilização de objetos que podem ser possíveis veículos para transmissão de patógenos, indicando-se a assepsia das mãos antes e após o uso dos aparelhos eletrônicos e também o uso de películas de revestimento com atividade antimicrobiana. A recomendação de álcool e outras substâncias químicas, apesar de comprovada eficácia, deve ser avaliada com cautela e deve-se seguir as recomendações dos fabricantes dos aparelhos eletrônicos.
\end{abstract}

Palavras-chave: Tecnologia; Telefone celular; Assepsia; Microbiologia; Fômites.

\begin{abstract}
The use of electronic devices such as cell phones, tablets, remote controls, notebooks, computers was intensified during the Covid-19 pandemic, where a large part of the population used remote services, abdicating face-to-face services, such as banking services, online shopping, orders, deliveries, education, as a way to keep distance. The present work aimed to indicate the main microorganisms present in electronic devices, the forms of contamination and the control methods reported in the literature. From this review, it was possible to perceive the potential for carrying microorganisms and propagating infectious diseases present in these objects. These are contaminated through direct contact with the skin or by salivary droplets. The residence time can vary from days to months depending on the microorganism and the material of the surface composition. As a means of prevention and control, resources such as coating films, based on nanotechnology, that present antimicrobial activity, aiming to limit the spread of microorganisms, are already available on the market. However, the search for chemical agents intended for use in electronic devices presents scarce data. From this study, the importance of preventive measures and care in the use of objects that can be possible vehicles for the transmission of pathogens is understood, indicating the asepsis of the hands before and after the use of electronic devices and also the use of coating films with antimicrobial activity, the recommendation of alcohol and other chemical substances, despite their proven efficacy, must be carefully evaluated and the recommendations of the manufacturers of electronic devices must be followed.
\end{abstract}

Keywords: Technology; Smartphone; Asepsis; Microbiology; Fomites.

\section{Resumen}

El uso de dispositivos electrónicos como celulares, tablets, controles remotos, notebooks, computadoras se intensificó durante la pandemia Covid-19, donde gran parte de la población utilizó servicios remotos, abdicando de los servicios presenciales, como los bancarios, compras online, pedidos, entregas, educación, como forma de mantener la distancia. El presente trabajo tuvo como objetivo señalar los principales microorganismos presentes en los dispositivos electrónicos, las formas de contaminación y los métodos de control reportados en la literatura. A partir de esta 
revisión, fue posible percibir el potencial de portar microorganismos y propagar enfermedades infecciosas presentes en estos objetos. Estos se contaminan por contacto directo con la piel o por gotitas de saliva. El tiempo de residencia puede variar de días a meses dependiendo del microorganismo y el material de la composición de la superficie. Como medio de prevención y control, ya se encuentran disponibles en el mercado recursos como películas de recubrimiento, basadas en nanotecnología, que presentan actividad antimicrobiana, con el objetivo de limitar la propagación de microorganismos. Sin embargo, la búsqueda de agentes químicos destinados a su uso en dispositivos electrónicos presenta datos escasos. A partir de este estudio se comprende la importancia de las medidas preventivas y cuidados en el uso de objetos que pueden ser posibles vehículos para la transmisión de patógenos, indicando la asepsia de las manos antes y después del uso de dispositivos electrónicos y también el uso de películas de recubrimiento. con actividad antimicrobiana, se debe evaluar cuidadosamente la recomendación del alcohol y otras sustancias químicas, a pesar de su probada eficacia, y se deben seguir las recomendaciones de los fabricantes de dispositivos electrónicos.

Palabras clave: Tecnología; Teléfono móvil; Asepsia; Microbiología; Fómites.

\section{Introdução}

A utilização de aparelhos eletrônicos como celulares, tablets, controles, notebooks, computadores e teclados está definitivamente inserida no cotidiano da população, pois estes facilitam não só o acesso da comunicação, como também são ferramentas importantes para muitas atividades, como para solicitar pedidos, compras, transações, solicitações de transporte, dentre outras finalidades. Um smartphone pode possuir diversos aplicativos que auxiliam na vida pessoal e profissional. Em apenas um aparelho, que cabe na palma da mão, é possível ter vários instrumentos reunidos, coisa que há alguns anos atrás necessitaria de um com junto de instrumentos individuais, como: câmera, agenda, rádio, vídeo game, livros, internet, televisão, aparelho de DVD, entre outros. Muitas destas funções foram consolidadas durante a pandemia da Covid-19, onde uma grande parte da população utilizou os serviços remotos ao invés dos presenciais como forma de distanciamento, como serviços de banco, compras online, encomendas, deliveries e, mesmo ensino.

O recente surto de Covid-19 é a terceira transposição documentada de um coronavírus cujo reservatório são animais a ser transmitido e causar doenças em humanos nas últimas duas décadas, após a severa síndrome respiratória aguda (SARS) em 2002 e a síndrome respiratória do Oriente Médio (SARM) em 2012 (Panigrahi et al., 2020). Isto trouxe o foco da epidemiologia às instituições de saúde e rapidamente este tema se inseriu nas discussões do cotidiano da população.

Desta forma, também deve ser dada atenção especial à manipulação de objetos eletrônicos, como por exemplo, os celulares que são frequentemente usados, estando em contato direto com as mãos e rosto, durante o manuseio podem atingir temperaturas favoráveis a sobrevivência e ao crescimento de microrganismos (Olsen, et al., 2020). Com isso, aparelhos celulares e equipamentos eletrônicos tem despertado o interesse pela possibilidade de ser um meio de transmissão de diversos patógenos, inclusive o Sars-Cov-2.

É possível perceber que objetos que são frequentemente utilizados pela população servem como veículo para microrganismos, os fômites são contaminados através de contato direto com a pele de algum indivíduo ou por gotículas salivares. Sendo que o tempo de permanência pode variar de dias a meses dependendo do microrganismo ou do material da superfície. Conforme Kramer et al. (2006) observaram que bactérias Gram positivas como Staphylococcus aureus e Streptococcus pyogenes podem sobreviver durante meses em objetos secos, sendo o plástico um material muito utilizado em vários objetos e em aparelhos eletrônicos um dos mais suscetíveis a um maior tempo de permanência de microrganismos.

Dessa forma, há a necessidade de desenvolvimento de estratégias para a higienização de aparelhos eletrônicos. Assim, alguns fabricantes já desenvolveram recomendações de higienização, entretanto, na falta de orientação recomenda-se a utilização de álcool 70\%, álcool isopropílico ou lenços descontaminantes (Panigrahi et al., 2020). Ressalta-se a necessidade de mais estudos sobre formas efetivas de descontaminação de aparelhos eletrônicos, que analisem a frequência que esses devem ser higienizados além de matérias eficazes que não comprometam a utilização dos equipamentos.

Este trabalho objetivou construir uma revisão bibliográfica sobre o tema presença de diversos tipos de microrganismos em aparelhos eletrônicos com o intuito de demonstrar os fatores que favorecem a contaminação, e os 
principais grupos encontrados, bem como reunir os métodos de controle efetivos reportados nos trabalhos pesquisados.

\section{Metodologia}

O presente artigo segue uma abordagem qualitativa sob o método de revisão bibliográfica de literatura, uma vez que objetiva a busca e síntese de pesquisas relevantes, visando maior compreensão e entendimento acerca da temática de investigação, de forma a beneficiar aspectos de análises científicas. Ainda, o método consiste na identificação de lacunas existentes, de forma a estimular a realização de novas pesquisas.

Para a sua condução foram seguidos os procedimentos descritos por Estrela (2018) e Galvão e Ricarte (2019). Foram pesquisados trabalhos científicos, publicados no período de 2000 a 2020 nas bases Scielo, Pubmed, Google Patents, Google Trends e periódicos CAPES, utilizando os seguintes descritores e suas respectivas traduções no idioma inglês: microrganismos, computador, bactéria, aparelhos eletrônicos, teclados, fômites.

\section{Resultados e Discussão}

\subsection{Microrganismos: O que são?}

Os microrganismos são seres tão minúsculos que não são possíveis de enxergar sem o auxílio de um microscópio. São considerados microrganismos: as bactérias, os fungos como as leveduras e bolores, protozoários e as algas microscópicas. Ademais os vírus, seres acelulares, também fazem parte dos ditos micróbios (Tortora et al., 2017). Fazem parte da vida dos seres humanos, pois estão presentem no próprio organismo, como também nos espaços cotidianos. Podem ser benéficos e úteis como por exemplo os microrganismos fermentadores utilizados na fabricação de pães, iogurtes, queijos, vinhos e vinagres, e também, como os que auxiliam na fertilização do solo.

Contudo, muitas espécies podem ser patogênicas, isto é, causar doenças, seja nos humanos, animais ou plantas. Um exemplo disso é a bactéria Staphyloccocus aureus, que apesar de ser encontrada com frequência em humanos saudáveis, certas cepas são capazes de causar desde infecções cutâneas até septicemia.

\subsection{Rotas de Transmissão dos Microrganismos}

Os microrganismos podem ser transmitidos do reservatório para o hospedeiro através de três caminhos: veículo, vetores e contato (Aguiar et al., 2008). A transmissão por veículos ocorre quando a propagação dos patógenos ocorre através da água, alimentos ou ar (Tortora et al., 2017). A água de consumo humano é o principal veículo de transmissão de patógenos causadores de infecções gastrointestinais (Siqueira et al. 2010).

Da mesma forma, os alimentos são susceptíveis à contaminação por diferentes agentes etiológicos, tornando-se um importante veículo para transmissão de doenças que afetam a saúde humana, como infecções e intoxicações ocasionadas pela ingestão de alimentos contaminados. Estas contaminações podem ocorrer através de matéria prima, manipulador, contaminação cruzada, utensílios etc. Ressalta-se que os principais fatores envolvidos na ocorrência destas doenças são o controle inadequado da temperatura durante o cozimento, o resfriamento e a estocagem, a higiene pessoal insuficiente, a contaminação cruzada entre produtos crus e processados e falhas no monitoramento dos processos (Forsythe, 2013).

Segundo dados da World Health Organization (WHO, 2020b), anualmente ocorrem, 600 milhões de casos, dos quais 420 mil resultaram em óbito, sendo os agentes mais frequentemente envolvidos dos microrganismos os patógenos entéricos de origem fecal, tais quais Escherichia coli, Salmonella spp. Norovírus e Campylobacter spp.

A transmissão por vetores é aquela cuja transmissão do patógeno se dá através de animais e insetos, como: ratos, baratas, moscas, formigas, carrapatos, pulgas, os quais possuem a capacidade de transportar microrganismos atuando dessa 
forma como veículos mecânicos (Silva et al., 2005). No estudo de Silva et al. (2005) que avaliaram o papel das formigas como veículo de transmissão de patógenos causadores de infecções hospitalares em um hospital de Alfenas, no estado de Minas Gerais/BR. Dentre as formigas coletadas 97,8\% delas estavam contaminadas. Pereira e Ueno (2008), por sua vez, verificaram o potencial de veiculação de patógenos por formigas, onde em 63,5\% das cepas isoladas foram caracterizadas como positivas para bacilos Gram positivos produtores de esporos, 6,3\% para bacilos Gram negativos, 23,1\% para cocos Gram positivos sendo que 59,2\% (19) das cepas foram de Staphylococcus coagulase-negativos e 40,2\% (29) foram de Micrococcus ou Stomatococcus, 6,3\% fungos com filamentos e 0,5\% para leveduras. Ambos os estudos fomentaram o potencial de associações das formigas com bactérias e com fungos tanto leveduriformes quanto filamentosos.

Várias doenças são transmitidas por vetores, como a dengue, malária, febre amarela, Chagas, Leishmaniose, entre outras. De acordo com dados da World Health Organization (WHO, 2020a), cerca de 17\% das doenças infecciosas são transmitidas por vetores através de picadas, mordidas e outros tipos de lesões que inserem o patógeno no tecido o que resulta em mais de um milhão de óbitos ao ano. De acordo com Tortora (2017) a transmissão por contato se dá por contato direto, conhecida também como transmissão pessoa a pessoa, quando não há um objeto intermediando, o agente entra em contato diretamente com a pessoa, como em toque, beijo, aperto de mão e relação sexual. Já a transmissão por contato indireto é quando há um objeto inanimado intermediando (fômite), como em copos, toalhas, dinheiro, controles, smartphone, câmeras (Figura 1).

Figura 1- Rotas de transmissão de microrganismos.

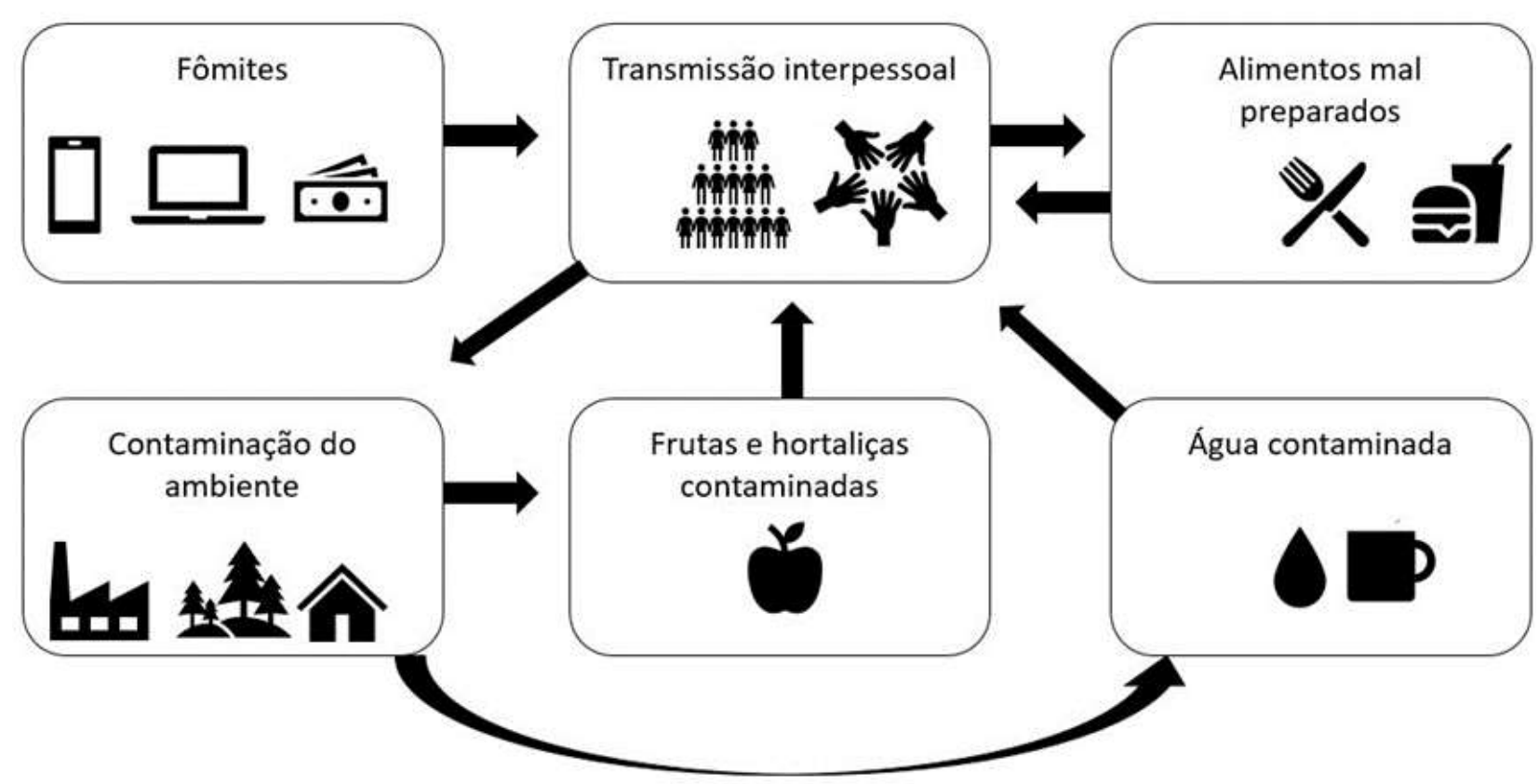

Fonte: Autores (2021).

De acordo com Araújo et al. (2017) a pele possui a capacidade de abrigar microrganismos e transferi-los de uma superfície para outra, através do contato direto ou indireto com objetos, sendo as mãos dos indivíduos o veículo para a disseminação de patógenos.

Geralmente a pele das mãos abrigam uma população de $10^{0}$ a $10^{6} \mathrm{UFC} / \mathrm{cm}^{2}$ de microrganismos que são divididos em microrganismos transitórios e residentes (Kumar et al., 2019; Mutters \& Warnes, 2019). A microbiota transitória é composta 
por microrganismos diversos que podem ser adquiridos através do contato com superfícies e ter ou não potencial de causarem doenças. Estes se localizam na superfície da pele e raramente, se multiplicam neste local, sendo facilmente removidos pela lavagem efetiva das mãos, como forma de evitar a sua disseminação e envolvimento em doenças. Já a microbiota residente é formada geralmente por microrganismos de baixa virulência que integram as camadas mais profundas da pele e que são de difícil remoção quando a higienização ocorre apenas com água e sabão (Santos et al., 2021).

Coelho et al. (2010) em seu estudo sobre contaminação microbiológica de ambientes e de superfícies em restaurantes comerciais, constataram que as mãos de $17 \%$ dos manipuladores de alimentos dos setores de carnes e cocção apresentaram contaminação na ordem $10^{6}$ UFC para microrganismos mesófilos aeróbios.

A transmissão por contato com gotículas se dá através de espirros, tosse, fala ou risada que liberam gotículas de muco (perdigotos) no ar e estas podem percorrer distâncias curtas, menos de um metro, do reservatório ao novo hospedeiro ou depositarem-se em objetos (Fonseca \& Silva, 2006 citado em Lacerda et al., 2014). No entanto, em uma pesquisa realizada no Instituto de Tecnologia de Massachusetts (MIT) que avaliou qual distância as partículas liberadas no espirro poderiam chegar, onde os pesquisadores captaram as imagens em câmera lenta a uma taxa de 30 a 2000 quadros por segundo, foi possível visualizar e medir a distância das partículas emitidas durante um espirro, que podem alcançar até oito metros (Bourouiba, 2020).

\subsection{Métodos de detecção de microrganismos em de aparelhos eletrônicos}

Dos trabalhos pesquisados verifica-se que todas as coletas foram realizadas a partir de esfregaço com swabs estéreis umedecidos em solução salina $(\mathrm{NaCl}$ 0,9\%) nas superfícies dos aparelhos eletrônicos. Os principais microrganismos, que os estudos objetivaram detectar foram microrganismos de origem entérica como bacilos Gram negativos, assim como os da família das enterobactérias, tais como, Escherichia coli, Klebsiella e Salmonella onde se utiliza principalmente o meio ágar MacConkey para a detecção, e no caso das bactérias Gram positivas foi voltada predominantemente para a detecção de Staphylococcus aureus, sendo essa uma bactéria amplamente distribuída, presentes comumente na pele, cabelo e também nas vias aéreas superiores dos humanos, cujo o principal meio de isolamento reportado foi o ágar Manitol. Já o ágar sangue foi utilizado tanto para detecção de bacilos Gram positivos quanto para bacilos Gram negativos, como pode ser observado a Tabela 1. 
Research, Society and Development, v. 10, n. 14, e359101422204, 2021

(CC BY 4.0) | ISSN 2525-3409 | DOI: http://dx.doi.org/10.33448/rsd-v10i14.22204

Tabela 1- Principais meios de detecção de microrganismos em aparelhos eletrônicos.

\begin{tabular}{|c|c|c|c|c|c|}
\hline Objeto & $\begin{array}{c}\text { Trabalho (autor, } \\
\text { ano) }\end{array}$ & Microrganismo & $\begin{array}{c}\text { Forma de } \\
\text { coleta }\end{array}$ & Técnica & Meios utilizados \\
\hline \multirow[t]{9}{*}{ Celulares } & Araujo et al., (2017) & Staphylococcus sp & Swab & Contagem em placas, & Ágar Manitol \\
\hline & & & & avaliação de & Salgado \\
\hline & & Enterobactérias & & resistência a & Ágar Mac Conkey \\
\hline & & & & antibióticos & \\
\hline & Nunes e Siliano & Enterobactérias & & Contagem em placas & MacConkey e Ágar \\
\hline & (2016) & & & & sangue \\
\hline & Teixeira e Silva & Staphylococcus aureus & & Contagem em placas & Ágar manitol \\
\hline & (2017) & & & & \\
\hline & & Bacilos Gram negativos & & & Ágar Mac conkey \\
\hline \multirow[t]{7}{*}{ Teclados } & Alves et al. (2014) & Staphylococcus aureus & $s w a b$ & Contagem em placas & Ágar Sangue \\
\hline & & & & & Ágar Manitol-Sal \\
\hline & & Enterobactérias & & Contagem em placas & Ágar Sangue \\
\hline & & & & & Ágar MacConkey \\
\hline & Silva et al. (2014) & Fungos & & Contagem em placas & Sabouraud Dextrose \\
\hline & & Bactérias & & Contagem em placas & Miller Hinton e \\
\hline & & & & & Ágar \\
\hline \multirow[t]{3}{*}{ IPad } & Kiedrowski et al. & Clostridium difficile & swab & Contagem em placas e & Ágar Seletivo \\
\hline & (2013) & & & teste a resistência a & \\
\hline & & Staphyloccus aureus & & meticilina & Ágar sangue \\
\hline
\end{tabular}

Fonte: Autores (2021).

\subsection{Presença de microrganismos em aparelhos eletrônicos}

Os aparelhos eletrônicos que hoje são amplamente utilizados como: celulares, teclados, mouses, controles, tablets e computadores podem ser veículos de microrganismos. A transmissão por fômite ocorre quando os microrganismos de uma pessoa que está infectada são depositados em um objeto inanimado e após será propagado em um novo hospedeiro (Lee et al., 2012 citado em Olsen et al., 2020).

Os microrganismos se transferem para aparelhos eletrônicos quando utilizados por alguma pessoa infectada, podendo ser portador assintomático através do contato com partes do corpo, ou de forma indireta, como por meio de gotículas salivares (Araújo et al., 2017). Em sua maioria, os aparelhos eletrônicos são compostos de plásticos, sendo esse um material favorável a permanência de microrganismos. Ao estudarem o tempo de permanência de patógenos em superfícies Kramer et al. (2006), constataram que bactérias Gram positivas que são facilmente isoladas podem permanecer viáveis durante meses em superfícies que não sejam molhadas. Já os vírus que acometem o trato respiratório como corona, influenza e SARS podem sobreviver por vários dias. Outro ponto do estudo foi relacionado ao tipo de material que pode colaborar com o tempo de permanência dos 
microrganismos, e constataram que das superfícies secas o plástico é mais propicio a persistência dos microrganismos.

Outro estudo que contribui é o de Desai et al. (2011), que ao avaliarem o potencial de transmissão de uma cepa de Staphylococcus aureus resistente à meticilina através de uma pele artificialmente contaminada por fômites ao longo do tempo, utilizando um conjunto de materiais porosos e não porosos como lâminas de barbear, brinquedos de plástico, cerâmica, sabão, madeira, vinil, toalhas, lençóis e ombreiras. Os autores observaram que algumas superfícies, principalmente as não porosas como o disco de vinil, permaneceram com um alto potencial de contaminação por mais de 8 semanas.

Ademais, muitos desses equipamentos são de difícil limpeza, por conterem peças pequenas como no caso de teclados e controles ou por possuírem telas sensíveis aos reagentes químicos, assim como pela falta de higiene dos indivíduos que utilizam tais aparelhos, como mostrado no estudo de Alves et al. (2014), o qual identificou microrganismos presentes em teclados de computadores, de amostragens distintas, sendo uma delas de lan houses do município de Jataí, Goiás, havendo aplicação de questionário aos administradores referente a higienização dos aparelhos, onde $58 \%$ dos estabelecimentos analisados, afirmaram que raramente ou nunca efetuavam a limpeza dos teclados e mouses. Aliado a isto, esses estabelecimentos vendiam alimentos aos seus clientes que poderiam consumir enquanto utilizavam os computadores, dessa forma oferecendo mais substrato orgânico para os microrganismos, juntamente com a grande alternância de pessoas que frequentavam o local diariamente, o que poderia explicar a alta frequência de microrganismos encontrados.

Os telefones celulares são objetos pequenos e facilmente transportáveis, que cabem muitas vezes nos bolsos, e estão cada vez mais inseridos no cotidiano da população. Conforme o Groupe Spéciale Mobile Association (GSMA, 2020), em 2019 cerca de 65\% da população mundial possuía um smartphone e estima-se que até o ano de 2025, $80 \%$ da população adquirirá um, como pode ser observado na Figura 2 (GSMA, 2020).

Figura 2- Representação gráfica da parcela da população mundial que possui smartphone em 2020 e estimativa de quantos irão adquirir até o ano de 2025

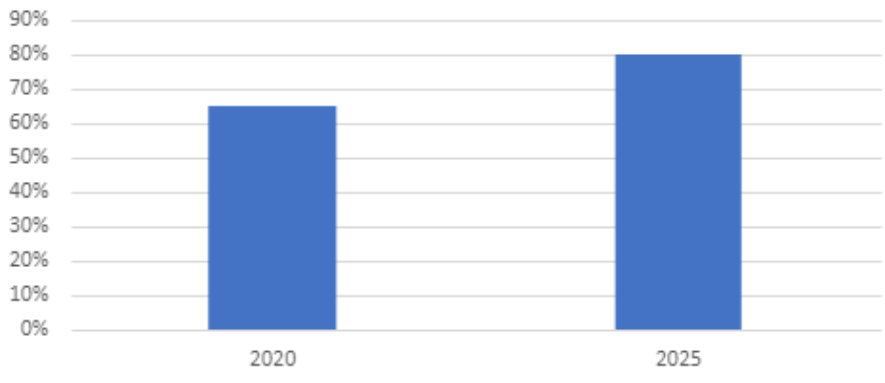

Fonte: Adaptado de GSMA (2020).

Já no Brasil, de acordo com o Instituto Brasileiro de Geografia e Estatística (IBGE, 2018) a parcela das residências que havia aparelho celular alcançou $93,2 \%$, onde $79,3 \%$ das pessoas com 10 anos ou mais possuem pelo menos um telefone celular para uso pessoal (Figura 3a e 3b). 
Figura 3- (a) Parcela brasileira que possuíam telefone celular em 2018; (b) Parcela populacional brasileira com 10 anos ou mais que possuíam aparelho celular para uso pessoal em 2018

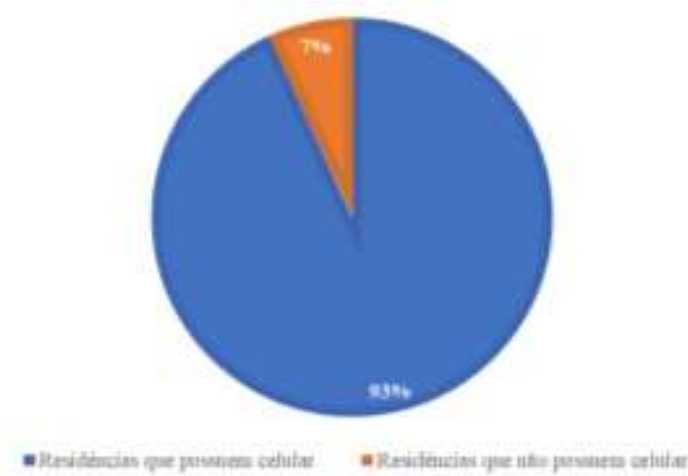

(a)

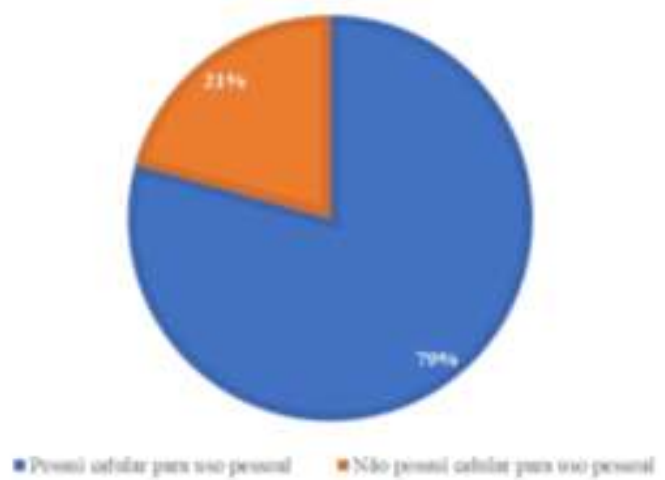

(b)

Fonte: Adaptado de IBGE (2018).

Com o avanço tecnológico, o ser humano passou a ter o mundo na palma da mão, seja para comunicação telefônica, transações bancárias, e mesmo compromissos de trabalho. Um smartphone pode possuir diversos aplicativos que podem auxiliar na vida pessoal e profissional, sendo esse sistema amplamente distribuído no mercado por apresentar uma gama de funções que, anteriormente, eram distribuídas em aparelhos separadamente.

Muitas destas funções foram consolidadas durante a pandemia da Covid-19, onde uma grande parte da população utilizou os serviços remotos ao em vez dos presenciais, como serviços de banco, compras online, encomendas, deliveries, ensino, como forma de distanciamento.

No entanto, deve ser dada atenção especial à manipulação desses objetos, apesar de possuírem diversos benefícios aos usuários podem causar alguns riscos, pois os celulares são frequentemente utilizados, como ao efetuar uma refeição, ou serem emprestados, estando assim suscetíveis aos microrganismos, ademais quando em contato direto com as mãos e rosto, durante o manuseio podem atingir temperaturas favoráveis a sobrevivência e ao crescimento de microrganismos (Olsen et al., 2020).

Diversos profissionais de várias áreas utilizam o aparelho celular como uma ferramenta em sua profissão, inclusive os profissionais da saúde, sendo utilizado tanto nos centros de saúde, como também por vezes na ala cirúrgica, já que pode ser empregado em múltiplas finalidades como, fotografar, preenchimento digital de ficha e catalogação, visualização de estudos, mídia didática para compreensão de pacientes entre outros.

Loyola et al. (2016) ao estudarem as bactérias do grupo Enterobactericeae em telefones de 114 profissionais de saúde pediátricos e neonatais peruanos em unidades de terapia intensiva (UTI), constataram que 47,4\% deles utilizavam o celular mais de 5 vezes durante o trabalho na UTI, sendo que $76 \%$ deles relataram jamais terem empregado qualquer tratamento para descontaminar o aparelho. Mais da metade $(53,5 \%)$ dos telefones durante o período de estudo foram contaminados por ao menos uma Enterobactericeae, sendo as mais comumente isoladas a Enterobacter spp., Escherichia coli, Klebsiella pneumoniae e Klebsiella oxytoca. Um terço das isoladas eram produtoras de $\beta$-lactamase de espectro estendido (ESBL), sendo que 53,3\% das bactérias eram multirresistentes (HCW), chegando à conclusão que telefones celulares podem colaborar com a disseminação de contaminações nas UTIs.

De acordo com Cunha et al. (2016), ao avaliarem a presença de microrganismos em um bloco cirúrgico, analisaram um total de 50 amostras de celulares dos profissionais da unidade, onde foi verificado que $88 \%$ dos aparelhos estavam colonizados por bactérias potencialmente causadoras de doenças, sendo os estafilococos coagulase negativa a bactéria mais 
encontrada, seguido do Bacillus subtilis e Micrococcus sp.

Segundo Nunes e Siliano (2016), ao realizarem a identificação de bactérias em 70 aparelhos celulares, constataram que 96\% deles estavam contaminados por ao menos uma espécie de bactéria, sendo o Staphylococcus sp. o gênero bacteriano mais frequente. Outro estudo que corrobora com estes fatos é o de Teixeira e Silva (2017) que avaliaram 30 telefones celulares, onde todas as amostras apresentaram crescimento microbiano, sendo positivas para coliformes fecais, que fazem parte do grupo das enterobactérias e o Staphylococcus aureus, uma bactéria presente nas mucosas, pele, cabelo de uma grande parte da população e distribuídos de forma ubíqua, no entanto, em certas situações são envolvidas em episódios de infecções, abcessos, podendo causar septicemia.

Conforme Olsen et al. (2020), alguns microrganismos presentes em telefones celulares podem criar resistência a antibióticos, o que representa grande perigo a saúde. Logo, é evidente que os aparelhos eletrônicos também são potenciais veículos de transmissão de microrganismos que podem causar riscos à saúde dos indivíduos (Alves et al., 2014; Nunes \& Siliano, 2016; Olsen et al., 2020). Sendo assim, a permanência de microrganismos em objetos inanimados é um fator que deve ser considerado, pois assim é possível saber o grau de exposição que as pessoas que frequentam o local estão sujeitas.

Alguns microrganismos que são considerados nocivos, mesmo em pequenas quantidades, podem ser encontrados após prolongado tempo em fômites (Silva et al., 2014). O que ressalta a importância da adoção de uma rotina de limpeza e desinfecção de superfícies potencialmente capazes de veicular patógenos e contribuir para a disseminação de doenças infecciosas.

Em 1946 o primeiro supercomputador do mundo foi inventado (ENIAC-100 KHZ), pesando 27 toneladas e utilizando 167 metros quadrados de área, em nada se parecia com os computadores que hoje são utilizados (Gale Academic Onefile, 2014). Os computadores pessoais, até recentemente, não eram tão comuns, sendo a internet até 1991, restrita aos órgãos governamentais e aos meios acadêmicos. É importante salientar que a internet é considerada a rede de computadores e que os sites, blogs e redes sociais fazem parte da web, ou seja, o conteúdo disponibilizado pela internet (Mendonça, 2015).

Vivemos na era da informação, muito relacionado ao advento dos computadores e da internet, atualmente transpomos barreiras físicas, com a internet tudo é rápido, tanto a comunicação quanto a interação com as pessoas ocorrem em tempo real. Quando a internet e computadores se inseriram no cotidiano das pessoas, muitas coisas mudaram, é utilizada para fins pessoais, educacionais e profissionais, seja no âmbito residencial, público ou privado.

Se apresenta nos ambientes por diversas formas, sejam desktop, notebook, tablets ou smartphones. Entretanto conforme dados da Instituto Brasileiro de Geografia e Estatística (IBGE, 2018), a utilização de internet nos computadores no Brasil tem perdido espaço em relação a utilização de celulares ou televisão do ano de 2017 para 2018, contudo dado ao atual contexto de pandemia da Covid-19, onde trabalhos e estudos estão sendo realizados de forma remota, ganhando cada vez mais espaço é possível que esses dados sofram alterações. Esses aparelhos normalmente possuem plástico em sua composição, além de telas que aquecem sendo esses aspectos favoráveis ao crescimento de microrganismos.

Diversos trabalhos reportam estas evidências, como no estudo de Alves et al. (2014), que ao analisar a presença de Staphylococcus aureus e enterobactérias de 139 teclados de computadores, tanto de uso pessoal quanto de uso coletivo, verificaram que $66,7 \%$ dos computadores de uso pessoal estavam contaminados por ao menos um microrganismo. Ao total foram isolados e identificados 62 tipos de bactérias, dentre elas a Escherichia coli, Klebsiella sp, Pantoea agglomerans e Staphylococcus aureus as mais encontradas. Já nos computadores de uso coletivo a contaminação foi de $78,2 \%$, sendo a Enterobacter sp e Klebsiella sp as enterobactérias mais presentes. Além disso, 58\% dos locais analisados informaram que dificilmente ou nunca realizaram a higienização dos teclados e mouses.

Já o estudo de Silva et al. (2014) corrobora com estes resultados, onde os pesquisadores avaliaram a ocorrência de microrganismos em teclados e mouses de uma instituição de ensino superior, e verificaram a presença de uma grande 
quantidade de bactérias isoladas, sendo principalmente encontradas as dos gêneros: Staphylococcus spp, Streptococcus spp, Enterococcus spp, Corynebacterium spp, Klebsiella spp, Escherichia spp, entre outros bacilos Gram negativos, bactérias potencialmente envolvidas em infecções, inclusive apresentado em alguns casos, resistência ao uso de medicamentos, como as causadoras de infecções hospitalar.

Rodrigues et al. (2012) ao estudarem a contaminação de 31 teclados de computadores por bactérias que eram utilizados em um hospital universitário do nordeste do Brasil, ao monitorarem as seguintes alas: Clínica obstétrica, médica e de maternidade, pediatria, setor de quimioterapia, UTI neonatal, enfermaria da ala oncológica, ala oftalmológica e alojamento encontram Acinetobacter baumanii, Pseudomonas stutzeri, Pseudomonas oryzihabitans, Enterobacter cancerogenus, Enterobacter cloacae, Enterococcus faecium, Sphingomonas paucimobilis, Rhizobium radiobacter. Sendo que a $P$. oryzihabitants, E. cancerogenus e S. paucimobilis mostraram resistência a antimicrobianos frequentemente indicados. Dessa forma, é visto que teclados de computadores possuem grande potencial de atuar no alastramento de patógenos, principalmente em locais de uso coletivo e principalmente em clínicas, evidenciando a necessidade da adoção de medidas preventivas para evitar a disseminação dos patógenos, como a higienização programada dos equipamentos.

\subsection{Controle de microrganismos em aparelhos eletrônicos}

Kiedrowski et al. (2013) em seu estudo analisaram a desinfecção de 20 Ipads de um hospital como meio de reduzir a contaminação por Clostridium difficile e Staphylococcus aureus resistentes a meticilina. Somente 3 aparelhos foram positivos para $S$. aureus, sendo que nenhum dos equipamentos apresentou quaisquer bactérias Gram negativas, sendo assim não houve crescimento de $C$. difficile. Conforme os autores, é possível que a baixa taxa de contaminação se deva a baixa incidência de organismos resistentes nas instalações, assim como medidas de controle de infecção, as quais incluem: limpeza monitorada, programa de manejo antimicrobiano e assepsia das mãos.

É suma importância a higienização dos aparelhos eletrônicos já que esses podem conter uma elevada carga microbiana além de poderem atuar como veículos de patógenos. Conforme Rodrigues et al. (2012), ao analisarem a contaminação de teclados de computadores, a cobertura com película protetora juntamente com medidas preventivas como a boa assepsia das mãos seriam maneiras eficazes para reduzir os microrganismos.

Em consultórios odontológicos é recorrentemente a exposição a vários patógenos, observando este fato Sriram et al. (2018), analisaram a eficácia do álcool isopropílico e a desinfecção através de radiação ultravioleta (UV) na descontaminação de 30 celulares utilizados por consultórios odontológicos. Em todos os celulares analisados havia a presença de microrganismos. Um grupo de 15 telefones foram limpos com toalhetes contendo álcool isopropílico a 70\% e deixados a secar por um período de 10 minutos, já a outra metade de aparelhos celulares foram mantidos em câmara de fluxo laminar de ar equipada com luz ultravioleta por 15 minutos. Ambos os grupos obtiveram uma redução significativa no número de colônias após a descontaminação, sendo que o grupo do álcool isopropílico obteve uma redução de carga microbiana de 79,89\%, já o grupo exposto a luz ultravioleta resultou em uma redução de $71 \%$. Ambos os agentes se mostraram eficazes na desinfecção. Outro ponto é que os dentistas participantes da pesquisa mostraram desconhecimento sobre limpeza de celulares e de medidas básicas de higienização destes aparelhos. Os autores recomendam que haja limpeza regular dos aparelhos celulares usados em consultórios odontológicos, além de boas práticas na higiene das mãos.

Kiedrowski et al. (2013) em seu estudo analisaram métodos de desinfecção do iPad, para isso limparam a superfície com compressas de álcool isopropílico 70\%, hipoclorito de sódio a 0,6\%, lenços de lixívia e com lenços de microfibra para lentes umedecido com água esterilizada. Após analisarem os resultados, constataram que lenços de lixívia foram eficientes em remover por completo os esporos inoculados, já o pano de microfibra foi consideravelmente mais eficaz que as com álcool para a remoção de esporos de Clostridium difficile da superfície da tela. Após a limpeza com pano umedecido só restou uma 
média de $0.93-\log _{10}$ UFC quando antes existiam 2.3- $\log _{10}$ UFC. Ademais, o pano de microfibra se mostrou efetivo para a eliminação de Staphylococcus aureus resistente à meticilina, entretanto não conseguiu eliminar por completo o $C$. difficile. Outrossim é que a eficácia do pano de microfibra umedecido se deva ao contato com atrito, sendo esse suficiente para remover esporos. Dado que houve uma limitação do pano tão somente umedecido para eliminar todos os patógenos, os autores indicam o uso de capas não porosas e películas de proteção para iPads, pois essas permitem o uso de agentes desinfetantes sem que comprometa o dispositivo e enfatiza-se a higienização das mãos.

Os álcoois são úteis para a higienização de mãos e alguns materiais já que evaporam rapidamente e não deixam resíduos. A concentração ideal é 70\% visto que é menos volátil (maior tempo de contato com a superfície) que o álcool 90\%, as soluções aquosas se apresentam mais efetivas, pois, para que haja desnaturação do microrganismo é necessário a presença de água. Para a limpeza de aparelhos eletrônicos o mais indicado é o álcool isopropílico em razão de apresentar uma menor concentração de água o que diminuiria as chances de as peças oxidarem (Tortora et al., 2017).

Em 2020 com a pandemia da Covid-19 observa-se que houve no Brasil um aumento na busca por higienização de aparelhos celulares, e nos Estados Unidos sobre películas antimicrobianas como pode ser observado nas figuras $4 \mathrm{a}$ e 4b, obtidas através de pesquisa na ferramenta Google Trends, que auxilia na visualização de tendências ao longo do tempo. Neste caso observa-se que o pico de popularidade sobre este tema ocorreu no período de 15 a 21 de março, que coincide com a adoção das medidas de distanciamento no país. Enquanto que o interesse pelo assunto permaneceu ativo nos Estados Unidos durante o período de levantamento de dados desta pesquisa.

Figura 4- Acompanhamento de termos buscados na internet através do Google trends, onde (a) Gráfico gerado pelo Google Trends indicando a pesquisa do termo: "como desinfetar celular", no Brasil, no período de 03 de novembro de 2019 até 10 de novembro de 2020. (b) Gráfico gerado pelo Google Trends indicando a pesquisa do termo: "antimicrobial film", nos Estados Unidos, no período de 24 de novembro de 2019 até 14 de novembro de 2020

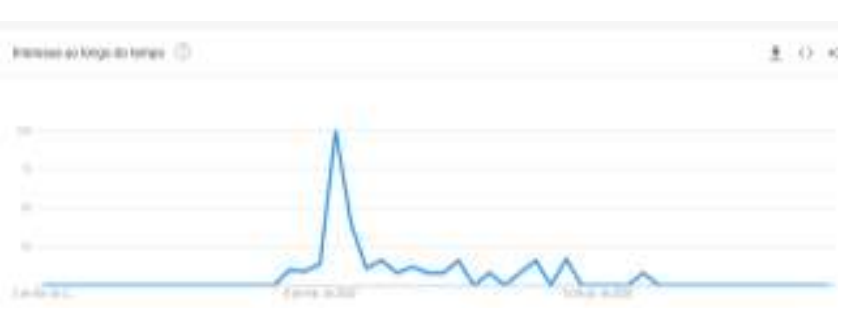

(a)

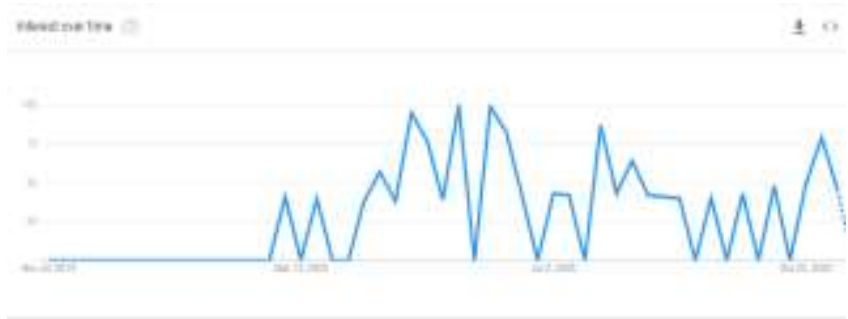

(b)

Fonte: Google Trends (2020).

Com isso, é visto que a pandemia fez com que aumentasse a preocupação com relação a adequada higiene dos objetos, já que esses podem estar contaminados com microrganismos patogênicos. Dessa forma, o mercado tem se atentado a esse novo nicho de demanda, e tem oferecido ao consumidor produtos diversos com a finalidade de revestir superfícies, seja de objetos como maçanetas e corrimãos, bem como de aparelhos eletrônicos como os celulares, com o intuito de proteger da contaminação microbiana, a maioria desses itens que alegam serem antimicrobianos dispõem em sua constituição íons de prata e íons cobre.

Ao realizar pesquisa no Google Patents, verificou-se que há registro de produtos como placas de vidros antimicrobianas, que possuem na sua constituição silício, prata e titânio e propõe ter bons efeitos antibacterianos e bactericidas além de ser à prova de impressão digital (Yongcong et al., 2020). Outro produto encontrado foi uma capa para celular antibacteriana, antimofo e antiviral que tem em sua composição nanopartículas de prata e dióxido de nano titânio. Além das 
propriedades antimicrobianas, a longo prazo o produto promete oferecer uma capa forte, resistente que não se desgasta facilmente além de boa aparência (Guangchuan et al., 2020).

Já em levantamento sobre os produtos à venda em lojas virtuais verificou-se que dentre os lançamentos já há disponível no mercado um revestimento adesivo que tem como base o cobre, que pode ser fixado em diversas superfícies como em botões de elevadores, corrimão, balcões, maçanetas entre outros, esse adesivo tem como promessa inativar 99,9\% dos fungos, bactérias e até mesmo alguns vírus como a MERS e o H1N1, os fundadores efetuaram pesquisa teste com o Sars-Cov2 em um laboratório nível 3 de biossegurança, obtendo como resultados preliminares uma eficácia de inativação de $77 \%$ do Sars-Cov-2 em período de tempo inferior a dois minutos, 95\% em cerca de 10 minutos, e superior a 99\% quando submetido a um tempo de 30 minutos, o que reduziria as chances de contaminação onde aplicado.

No estudo de Van Doremalen et al. (2020), foi constatado que o Sars-Cov-2 pode permanecer ativo em superfícies de plástico e de aço inox por um período de até 3 dias. Contudo, nas superfícies de cobre o vírus se torna inativo em minutos, sendo suprimido após 4 horas. Já Warnes et al. (2015), observaram quais os materiais são mais suscetíveis a permanecerem infecciosos com o coronavírus humano. O coronavírus sobrevive em seu estado infeccioso em diversos materiais, contudo foi observado que houve uma rápida inativação em latão e superfícies de cobre e níquel em temperatura ambiente de $21^{\circ} \mathrm{C}$. Sendo que o latão contendo ao menos $70 \%$ de cobre mostrou-se muito eficaz para a inativação, onde a taxa de inativação era diretamente proporcional à porcentagem de cobre.

O coronavírus é inativado em superfícies que contenham cobre devido a fragmentação do genoma viral, dessa forma a inativação é garantida e irreversível. Metais pesados como prata e cobre possuem efeito oligodinâmico, isso é, pequenas quantidades apresentam ação antimicrobiana (Tortora et al., 2017).

\section{Considerações Finais}

É possível perceber que os aparelhos eletrônicos, que são frequentemente utilizados pela população, servem como veículo para microrganismos, os fômites são contaminados através de contato direto com a pele de algum indivíduo ou por gotículas salivares, sendo que o tempo de permanência pode variar de dias a meses dependendo do microrganismo ou do material da superfície. Para auxiliar na desinfecção, há no mercado recursos como superfícies biocidas que ao oferecerem atividade antimicrobiana, as quais podem ser uteis para limitar a propagação de microrganismos.

A partir dessa pesquisa é compreendido a importância das medidas preventivas e cuidados na utilização de objetos que podem ser possíveis veículos para transmissão de patógenos, indicando-se medidas como assepsia das mãos antes e após o uso dos aparelhos eletrônicos e também o uso de películas de revestimento com atividade antimicrobiana, a recomendação de álcool e outras substâncias químicas, apesar de comprovada eficácia, deve ser avaliada com cautela e seguir as recomendações dos fabricantes dos aparelhos eletrônicos.

Considerando o surgimento recente de novos agentes patogênicos microbianos de rápida e ampla disseminação, como por exemplo, o Sars-Cov-2, aliada a inserção das tecnologias eletrônicas no cotidiano da maioria da população sugere-se em estudos futuros a pesquisa sobre agentes químicos que possam ser utilizados sem danificar aparelhos eletrônicos.

\section{Referências}

Aguiar, D.F., Lima, A.B.G. \& Santos, R.B. (2008). Uso das precauções-padrão na assistência de enfermagem: um estudo retrospectivo. Escola Anna Nery. 12 (3), 571-576. https://www.scielo.br/j/ean/a/K4xjS6gXkHSfZZQTRLqwrDP/?lang=pt

Alves, J.L.B., Costa, R.M.C. \& Braoios, A. (2014). Teclados de computadores como reservatórios de micro-organismos patogênicos. Journal Health Sciences Institute. 32 (1), 7-11. https://repositorio.unip.br/wp-content/uploads/tainacan-items/34088/34763/V32_n1_2014_p7a11.pdf 
Araújo, A.M., Novais, V.P., Calegari, G.M., Góis, R.V., Sobral, F.O.S. \& Marson, R.F. (2017). Ocorrência de microrganismos em aparelhos celulares no município de Ji-Paraná-Rondônia, Brasil. Brazilian Journal of Surgery and Clinical Research. 19 (1), 10-15. https://www.mastereditora.com.br/periodico/20170605_154800.pdf

Bourouiba L. (2020). Turbulent Gas Clouds and Respiratory Pathogen Emissions: Potential Implications for Reducing Transmission of COVID19. JAMA. 323 (18), 1837-1838. https://jamanetwork.com/journals/jama/fullarticle/2763852.

Brasil. (2009). Agência Nacional de Vigilância Sanitária. Segurança do Paciente em Serviços de Saúde: Higienização das Mãos / Agência Nacional de Vigilância Sanitária. Brasília: Anvisa, 2009. 105p. https://bvsms.saude.gov.br/bvs/publicacoes/seguranca_paciente_servicos_saude_higienizacao_maos.pdf.

Cunha, C.B.C., Moraes, F.R., Monteiro, V.S., Gomes, F., Feitosa, M.A. \& Silva, I.T.C. (2016). Avaliação microbiológica dos aparelhos celulares de profissionais do Bloco Cirúrgico em um Hospital beneficente. Revista de Epidemiologia e Controle de Infecção. 6 (3), $120-124$.

Coelho, A.I.M., Milagres, R.C.R.M., Martins, J.F.L., Azeredo, R.M.C. \& Santana, A.M.C. (2010). Contaminação microbiológica de ambientes e de superfícies em restaurantes comerciais. Ciência \& Saúde Coletiva. 15, 1597-1606.

Desai, R., Pannaraj, P.S., Agopian, J., Sugar, C.A, Liu, G.Y. \& Miller, L.G. (2011). Survival and transmission of community-associated methicillin-resistant Staphylococcus aureus from fomites. American Journal of Infection Control. 39, (3), 219-225. https://pubmed.ncbi.nlm.nih.gov/21458684/

Estrela, C. (2018). Metodologia científica: ciência, ensino, pesquisa. Artes Médicas.

Fonseca, J.F.A. \& Silva S.B.R. (2006). Hospital Geral Universitário: Manual de Precauções e Isolamento. https://online.unisc.br/seer/index.php/epidemiologia/article/download/4952/3985

Forsythe, S. J. (2013). Microbiologia da segurança dos alimentos. Artmed Editora.

Gale Academic Onefile. (2014). Computadores: por pouco eles não foram inventados um século antes. https://go.gale.com/ps/i.do?p=AONE\&u=capes\&id=GALE|A374627823\&v=2.1\&it=r\&sid=AONE\&asid=463606f6

Galvão, M. C. B., \& Ricarte, I. L. M. (2019). Revisão sistemática da literatura: conceituação, produção e publicação. Logeion: Filosofia Da Informação, 6(1). https://doi.org/10.21728/logeion.2019v6n1.p57-73

GSMA. (2020). The mobile economy. https://www.gsma.com/mobileeconomy/wpcontent/uploads/2020/03/GSMA_MobileEconomy2020_Global_Infographic.pdf

Guangchuan, C., Hongguang, Y. \& Xinlei, W. (2020). Antibacterial, mildewproof and antiviral composition for mobile phone shell, mobile phone shell and preparation method and application of antibacterial, mildewproof and antiviral composition. https://patents.google.com/patent/CN111567560A/en?q=coat;+cellphone;+antimicrobial\&after=priority:20200101

IBGE EDUCA. (2018). Uso de internet, televisão e celular no Brasil. https://educa.ibge.gov.br/jovens/materias-especiais/20787-uso-de-internet-televisao-ecelular-no-brasil.html\#: :text=Celular\%20\%C3\%A9\%20o\%20equipamento\%20mais,principal\%20de\%20acesso\%20\%C3\%A0\%20Internet

Kiedrowski, L.M., Perisetti, A., Loock, M.H., Khaitsa, M.L. \& Guerrero, D.M. (2013). Disinfection of iPad to reduce contamination with Clostridium difficile and methicillin-resistant Staphylococcus aureus. American Journal of Infection Control. 41 (11), 1136-1137. https://www.ajicjournal.org/article/S01966553(13)00193-4/fulltext

Kramer, A., Schwebke, I. \& Kampf, G. (2006). How long do nosocomial pathogens persist on inanimate surfaces? A systematic review. Biology Medicine Central Infectious Diseases. 6 (1), 130. https://pubmed.ncbi.nlm.nih.gov/16914034/

Kumar, K. V., Pal, A., Bai, P., Kour, A., E, S., P, R., Kausar, A., Chatterjee, M., Prasad, G., Balayan, S., Dutta, P., \& Wijesekera, K. (2019). Co-aggregation of bacterial flora isolated from the human skin surface. Microbial Pathogenesis, 135. https://doi.org/10.1016/j.micpath.2019.103630

Lacerda, M. K. S., de Souza, S. C. O., Soares, D. M., da Silveira, B. R. M., \& Lopes, J. R. (2014). Precauções padrão e Precauções Baseadas na Transmissão de doenças: revisão de literatura. Revista de Epidemiologia e Controle de Infecção, 4(4), 254-259. https://doi.org/10.17058/reci.v4i4.4952

Lee, G. \& Bishop, P. (2012). Microbiology and infection control for health professionals. Pearson Higher Education. Austrália: Pearson Higher Education.

Loyola, S., Gutierrez, L.R., Horna, G., Petersen, K., Agapito, J., Osada, J., Rios, P., Lescano, A.G. \& Tamariz, J. (2016). Extended-spectrum $\beta$-lactamaseproducing Enterobacteriaceae in cell phones of health care workers from Peruvian pediatric and neonatal intensive care units. American Journal of Infection Control. 44 (8), 910-916. https://pubmed.ncbi.nlm.nih.gov/27067520/

Mendonça, J. A. de (2015). Sociedade digital da informação e comunicação: uma história em construção. Revista Científica das Áreas de Humanidades. 8 (2), 18-26. https://revistas.unibh.br/dchla/article/view/1614

Mutters, R., \& Warnes, S. L. (2019). The method used to dry washed hands affects the number and type of transient and residential bacteria remaining on the skin. Journal of Hospital Infection, 101(4). https://doi.org/10.1016/j.jhin.2018.12.005

Nunes, K.O. \& Siliano, P.R. (2016). Identificação de bactérias presentes em aparelhos celulares. Science in Health. 7 (1), 22-25. http://arquivos.cruzeirodosuleducacional.edu.br/principal/new/revista_scienceinhealth/19_jan_abr_2016/Science_07_01_22-25.pdf

Oliveira, M.M.M., Brugnera, D.F., Mendonça, A.T. \& Piccoli. R.H. (2008). Condições higiênico-sanitárias de máquinas de moer carne, mãos de manipuladores e qualidade microbiológica da carne moída. Ciência e Agrotecnologia. 32 (6), 1893-1898. https://www.scielo.br/j/cagro/a/Gj4D7KZS8JNYH3tpTtLVWHg/?lang=pt

Panigrahi, S.K., Pathak, V.K., Kumar, M.M., Raj, U. \& Priya, K. (2020). Covid-19 and mobile phone hygiene in healthcare settings. British Medical Journal Global Health. 5 (4), e002505. https://gh.bmj.com/content/5/4/e002505 
Research, Society and Development, v. 10, n. 14, e359101422204, 2021

(CC BY 4.0) | ISSN 2525-3409 | DOI: http://dx.doi.org/10.33448/rsd-v10i14.22204

Pereira, R.S. \& Ueno, M. (2008). Formigas como veiculadoras de microrganismos em ambiente hospitalar. Revista da Sociedade Brasileira de Medicina Tropical. 41 (5), 492-495. https://www.scielo.br/j/rsbmt/a/gmpBcypfDk6L3dwrHKBfhCG/?lang=pt

Rodrigues, A.G., Viveiros, M., Barroso, I., Cavalcante, A.P. \& López, A. (2012). Contaminação bacteriana em teclados de computadores utilizados em hospital universitário do nordeste do Brasil. Medicina (Ribeirão Preto). 45 (1), 39-48. https://www.revistas.usp.br/rmrp/article/view/47570

Santos, M. C. Q. dos, Carvalho, L. M. A. de, Farias, A. J. A. de, Mendes, J. M. S., Morais, G. S. da N., Medeiros, A. C. T. de, Pessoa, M. S. de A., Farias, A. D. A. de, \& Neves, H. B. B. (2021). Eficácia de métodos de degermação cirúrgica: Uma revisão integrativa. Research, Society and Development, 10(8), e23810817292. https://doi.org/10.33448/rsd-v10i8.17292

Silva, L.T., Pichara, N.L., Pereira, M.A. \& Fiorini, J.E. (2005). Formigas como veículo de patógenos no Hospital Universitário Alzira Velano, em AlfenasMG. Revista Médica de Minas Gerais. 15 (1), 13-6. http://www.rmmg.org/artigo/detalhes/1450

Silva, M.H.R. da, Gotardi, A.H.B., Barros, A.A.S., Blini, R.C.B., Bernardes, L.G., Machado, A.R.S.R., Guerra, O.G. \& Machado, A.M. (2005). Isolamento e identificação de microrganismos presentes em superfícies de teclados e mouses de uma universidade de Três Lagoas, MS. Colloquium Vitae. 6 (3), 83-94. http://revistas.unoeste.br/index.php/cv/article/view/1255

Siqueira, L.P., Shinohara, N.K.S., Lima, R.M.T., PAIVA, J.E., Filho, J.L.L. \& Carvalho, I.T.C. (2010). Avaliação microbiológica da água de consumo empregada em unidades de alimentação. Ciência \& $\quad$ Saúde Coletiva. https://www.scielo.br/j/csc/a/nvqTQdwWcChssBvDcqCTwMD/abstract/?lang=pt

Sriram, S., Kumar, P.D.M., Swaminathan, R., Venkatesh, R. \& Menaka, V. (2018). Effectiveness of isopropyl alcohol and ultraviolet based sanitizer on decontamination of mobile phones used by dental personnel. Infection, Disease \& Health. 06(1), 9-22. https://www.researchgate.net/publication/326861208_Effectiveness_of_isopropyl_alcohol_and_ultraviolet-

based_sanitiser_on_decontamination_of_mobile_phones_used_by_dental_personnel

Teixeira, F.N. \& Silva, C.V. (2017). Análise microbiológica em telefones celulares. Revista F@ pciência. 11 (3), 15-24. http://www.fap.com.br/fapciencia/11_edicao/003.pdf

Tortora, G., Funke, B. \& Case, C. (2017). Microbiologia. Porto Alegre: Artmed.

Van Doremalen, N., Bushmaker, T., Morris, D.H., Holbrook, M.G., Gamble, A., Williamson, B.N., Tamin, A., Harcourt, J.L., Thornburg, N.J., Gerber, S.I., Lloyd-Smith, J.O., Wit, E. \& Munster, V.J. (2020). Aerosol and surface stability of SARS-CoV-2 as compared with SARS-CoV-1. New England Journal of Medicine. 382, (16), 1564-1567. https://www.nejm.org/doi/full/10.1056/nejmc2004973

Warnes, S.L.; Little, Z.R. \& Keevil, C.W. (2015). Human coronavirus 229E remains infectious on common touch surface materials. Microbiology. 6 (6). https://journals.asm.org/doi/full/10.1128/mBio.01697-15

WHO. (2020). Vector-borne diseases. https://www.who.int/en/news-room/fact-sheets/detail/vector-borne-diseases

WHO. (2020). Food safety. https://www.who.int/health-topics/food-safety/ 